\title{
MENELAAH PELAKSANAAN PENGANGKATAN HAKAM PADA PERKARA SYIQAQ DI PENGADILAN AGAMA INDONESIA DAN MAHKAMAH SYAR'IYAH MALAYSIA Arne Huzaimah*
}

\begin{abstract}
Syiqaq is a constant dispute and quarrel between husband and wife. To overcome the problem of syiqaq, then Allah SWT has arranged it directly in the Qur'an, the letter an-Nisa (4) verse 35, namely by adopting the hakam that comes from the family of each party to reconcile the two husband and wife. The implementation of the appointment of the rights applied in the procedural law of the religious court in Indonesia is not imperative, it all depends on the judge's judgment. Hakam in the Indonesian Religious Court only functions to reconcile the two parties (husband and wife) who are at loggerheads and not the authority to decide. So Hakam only serves as a mediator not an arbitrator. At the Malaysian Syar'iyyah Court, Hakam must obtain full authority from his principal. Husband may give full authority to the husband Hakam to pronounce divorce to his wife before the Court, and the wife can give full power to his wife Hakam to do khuluk or accept Lafaztalak before the Court.
\end{abstract}

Kata Kunci : Hakam, Pengadilan Agama, Mahkamah Syar’̈yyah.

Perkawinan adalah ikatan lahir bathin antara seorang pria dengan wanita yang diharapkan di dalamnya tercipta keluarga yang sakinah, mawaddah wa rahmah. Untuk mencapai hal tersebut diperlukan adanya saling pengertian dan saling memahami kepentingan kedua belah pihak, terutama yang terkait dengan hak dan kewajiban.Dalam kehidupan rumah tangga sering dijumpai adanya problema antara suami istri yang disebabkan karena tidak terpenuhinya hak yang seharusnya diperoleh atau tidak terlaksananya kewajiban dari salah satu pihak, atau karena alasan lain yang dapat menimbulkan suatu perselisihan antara suami istri tersebut. Dan terkadang mengarah pada putusnya ikatan perkawinan. Perselisihan dan pertengkaran suami istri yang terus menerus terjadi, dalam Islam dikenal dengan istilah syiqaq.

Kata syiqaq berasal dari bahasa Arab شَاقَ - يُشاقُ - مُشاقًا و شِقاقًا sisi; perselisihan; (khilaf); perpecahan; permusuhan; (al adawah); pertentangan atau persengketaan. (Somad, 2012: 304), sehingga padanan katanya perselisihan (al khilaf); perpecahan; permusuhan (al adawah).

Muhammad Ali Ash Shabuni, menjelaskan bahwa yang dimaksud Syiqaq adalah "Perselisihan dan permusuhan, yang diambilkan dari kata asy syaqqu yang bermakna sisi, dikarenakan setiap kedua pihak yang berselisih berada pada sisi yang berbeda satu sama lain yang disebabkan oleh permusuhan dan ketidakjelasan." (Shabuni, t.t: 332).

Ahmad Mushtafa al Maraghi, juga menjelaskan bahwa Syiqaq adalah "perselisihan yang berpotensi membuat dua pihak berpisah, dan ketakutan masing-masing pihak akan terjadinya perpisahan itu dengan lahirnya sebabsebab perselisihan." (al Maraghi, 1974: 49). Dan menurut Taisyir Rajab At

*Program Doktor Ilmu Hukum Fakultas Hukum UNSRI, email: huzaimah172@gmail.com. 
Tamimi, syiqaq adalah "Pertengkaran yang terjadi antara suami istri yang membutuhkan jawaban hukum oleh dua orang hakam apakah bisa berdamai atau berpisah" (at Tamimi, 2009: 229).

Berbeda dengan pendapat ulama di atas, Sayyid Sabiq menyatakan bahwa dalam syiqaq harus ada unsur dharar, seperti yang dijelaskan dalam pengertian Syiqaq adalah "Perpecahan antara suami istri sehingga timbul permusuhan yang dikhawatirkan mengakibatkan pisah dan hancurnya rumah tangga. Harus ada unsur dharar atau membahayakan." (Sabiq, tt: 122). Adapun bentuk dharar menurut Imam Malik dan Hambal adalah suami suka memukul, suka mencaci, suka menyakiti badan jasmani istrinya, dan memaksa istrinya untuk berbuat munkar (Manan, 2009: 385).

Sedangkan Rasyid Ridha menjelaskan bahwa Syiqaq adalah perselisihan antara suami istri, perselisihan itu mungkin disebabkan karena istri nusyuz atau mungkin juga karena suami berbuat kejam dan aniaya kepada istri. (Ridha, t.t: 385). Hal senada juga dikemukakan oleh Madzhab Syafi'iyah yang dikemukakan oleh Zakariyah al Anshari dan Asy Syarbaini, syiqaq adalah perselisihan antara suami istri, dan perselisihan ini sangat memuncak serta dikhawatirkan terjadi kemudharatan apabila perkawinan diteruskan (isytidaadusysyiqaq).

Dari beberapa pendapat para ahli dapat diambil kesimpulan bahwa pengertian syiqaq terdapat 2 (dua) klasifikasi yaitu:

a. Syiqaq bermakna hanya perselisihan dan pertengkaran suami istri yang menyebabkan ketidak rukunan yang berpotensi terjadinya perceraian;

b. Syiqaq bermakna perselisihan dan pertengkaran suami istri yang mengandung unsur dharar atau membahayakan bagi salah satu pihak, yang berpotensi terjadinya perceraian.

Untuk mengatasi syiqaq yang terjadi antara suami istri tersebut, maka Allah telah mengaturnya secara langsung yaitu berupa pengangkatan hakam, sebagaimana tetuang dalam Al Qur'an Surat Annisa(4) ayat 35 yang Artinya: "Dan jika kamu khawatir ada persengketaan antara keduanya, maka kirimlah seorang hakam dari keluarga laki-laki dan seorang hakam dari keluarga perempuan. Jika kedua orang hakam itu bermaksud mengadakan perbaikan, niscaya Allah memberikan taufik kepada suami istri itu".

Indonesia dan Malaysia adalah dua diantara negara muslim yang berada di kawasan Asia Tenggara. Indonesia memberlakukan hukum keluarga Islam bagi penduduk yang beragama Islam berdasarkan UndangUndang Nomor 1 Tahun 1974 tentang Perkawinan dan Peraturan Pemerintah Nomor 9 Tahun 1975 tentang Peraturan Pelaksanaan UU Nomor 1 Tahun 1974, serta Kompilasi Hukum Islam (KHI). Apabila hukum materil keluarga Islam dilanggar, maka para pihak dapat mengajukan gugatan atau permohonan ke Pengadilan Agama berdasarkan UndangUndang Nomor 7 Tahun 1989 jo Undang-Undang Nomor 3 Tahun 2006 jis Undang-Undang Nomor 50 Tahun 2009. Berkaitan dengan perkara syiqaq, maka Pengadilan Agama juga menerapkan hukum acara syiqaq berupa pengangkatan hakam dalam proses pemeriksaan perkara tersebut berdasarkan Pasal 76 Undang-Undang Nomor 7 Tahun 1989. Di negara Malaysia juga diberlakukan hukum keluarga Islam berdasarkan Act 1984 
Nomor 303. Pengangkatan hakam diatur dalam seksyen 48 hukum keluarga Islam Act 1984 Nomor 303.

Tulisan ini akan memerikan gambaran tentang pelaksanaan pengangkatan hakam dalam perkara syiqaq yang diterapkan di negara Indonesia dan Malaysia.

\section{Pelaksanaan Pengangkatan Hakam di Pengadilan Agama Indonesia.}

Pengangkatan hakam dalam perkara perceraian dengan alasan syiqaq berlandaskan pada ketentuan Pasal 76 ayat (2) Undang-Undang Nomor 7 Tahun 1989 tentang Peradilan Agama yang menyebutkan bahwa: "Pengadilan setelah mendengar keterangan saksi tentang sifat persengketaan antara suami istri dapat mengangkat seorang atau lebih dari keluarga masing-masing pihak ataupun orang lain untuk menjadi hakam”.

Pengertian hakam dalam praktik Peradilan Agama di Indonesia dapat ditemukan dalam Penjelasan Pasal 76 ayat (2) Undang-Undang Nomor 7 Tahun 1989 tentang Peradilan Agama yang menjelaskan : "Hakam adalah orang yang ditetapkan Pengadilan dari pihak keluarga suami atau pihak keluarga istri atau pihak lain untuk mencari upaya penyelesaian perselisihan syiqaq".

Menurut ketentuan hukum acara peradilan agama, pengangkatan hakam sebagai tindakan "sunnah" bukan wajib. Hal ini dapat dipahami dari teks Pasal 76 ayat (2) undang-Undang Nomor 7 Tahun 1989 yang menyebutkan: "Pengadilan ....dapat mengangkat seorang atau lebih dari keluarga masing-masing pihak atau pun orang lain untuk menjadi hakam". Pengadilan "dapat" mengangkat hakam. Bukan "wajib" mengangkat hakam, tetapi "dapat" mengangkat hakam. Menurut Yahya Harahap, pengangkatan hakam di Pengadilan Agama merupakan tindakan kasuistik. Tergantung pada pendapat dan penilaian Hakim. Walaupun ada permintaan dari salah satu pihak atau kedua belah pihak, semua tergantung pada pendapat dan penilaian Hakim atas ukuran mana yang lebih mendatangkan "maslahat" dalam penyelesaian perkara syiqaq tersebut. (Harahap, 1993: 275-276).

Ketentuan dalam praktik pengadilan agama di Indonesia, berdasarkan Pasal 76 ayat (2) Undang-Undang Nomor 7 Tahun 1989 bahwa hakam tersebut tidak harus dari keluarga suami istri, diperbolehkan mengangkat hakam dari pihak lain. Rumusan dalam Penjelasan Pasal 76 ayat (2) Undang-Undang Nomor 7 Tahun 1989 sengaja diperluas oleh pembuat undang-undang dengan tujuan agar rumusan dalam surat An Nisa' (4) ayat 35 dapat dikembangkan untuk menampung berbagai problema dalam kehidupan masyarakat sepanjang dalam batas-batas acuan jiwa dan semangat yang terkandung dalam ayat tersebut. (Harahap, 1993: 271).

Kalaupun ingin mengangkat hakam dari pihak keluarga, maka harus dipertimbangkan faktor wibawa dan kearifan. Karena apabila pihak keluarga tidak memiliki pengaruh atau wibawa maupun kearifan pribadi, maka tidak ada gunanya memprioritaskan hakam dari pihak keluarga. Lebih baik ditunjuk pihak lain yang benar-benar arif dan berwibawa terhadap suami istri tersebut. Oleh karena itu, ditinjau dari segi pendekatan proses arus horizontal, maka perumusan Pasal Penjelasan Pasal 76 ayat (2) Undang-Undang Nomor 7 Tahun 1989 tidak bertentangan dengan jiwa dan semangat surat An Nisa' (4) ayat 35. 
Adapun untuk menjadi hakam, harus memenuhi beberapa persyaratan. Menurut Sayyid Sabiq disyaratkan terdiri dari orang laki-laki yang berakal, baligh, adil, dan Islam. Tidak disyaratkan harus dari keluarga suami-istri, boleh berasal dari pihak luar. (Sabiq, 1980)

Syekh Abdul 'Aziz Al Khuli mensyaratkan seseorang yang dapat diangkat menjadi hakam adalah sebagi berikut:

1. Berlaku adil di antara para pihak yang berperkara.

2. Dengan ikhlas berusaha mendamaikan suami istri.

3. Kedua hakam itu disegani oleh kedua belah pihak.

4. Hendaklah berpihak kepada yang teraniaya/dirugikan. Apabila pihak yang lain tidak mau bersama.

Wahbah Al-Zuhayly mensyaratkan hakam dalam syiqaq adalah lakilaki, adil waspada/teliti, sunah dari pihak keluarga jika tidak ada hakim bisa mengangkat yang lain, lebih utama jika tetangga yang memahami kondisi, dan dipatuhi mereka. (Az-Zuhayly, 1989: 528). Berpedoman pada ketentuan dalam Pasal 76 ayat (2) Undang-Undang Nomor 7 Tahun 1989 tersebut. Pengadilan Agama baru dapat mengangkat hakam setelah pemeriksaan pembuktian selesai. Saksi-saksi dan alat bukti yang lain telah selesai diperiksa oleh hakim. Dari hasil pemeriksaan pembuktian, Hakim telah mendapatkan gambaran tentang sifat persengketaan yang terjadi antara suami istri. Pada tahap tersebut, barulah hakim dapat menunjukan atau mengangkat hakam.

Yahya Harahap menjelaskan bahwa rasio tatacara pengangkatan hakam yang demikian itu adalah agar Pengadilan atau Hakim harus terlebih dahulu mengetahui secara seksama apa dan bagaimana perselisihan dan pertengkaran suami istri, dan faktor yang melatar belakangi, sehingga Hakim dapat memberi bekal kepada hakam tentang segala sesuatu yang ditemukan di persidangan untuk dijadikan sebagai bahan menjajaki usaha penyelesaian perselisihan. Hakim harus menyampaikan kepada hakam tentang segala sesuatu yang terjadi di persidangan agar hakam dapat bekerja sebaik mungkin. (Harahap, 1993: 273-274). Selain itu, hakam juga diberi pengarahan seperlunya, batas jangka waktu penugasan serta waktu melaporkan hasil usahanya.

Adapun pihak yang berwenang mengangkat hakam berdasarkan ketentuan Pasal 76 ayat (2) Undang-Undang Nomor 7 Tahun 1989 tentang Peradilan Agama, adalah Pengadilan, yang dalam hal ini dilakukan oleh Ketua Majelis Hakim yang memeriksa perkara. Namun, belum terdapat aturan khusus tentang tatacara pengangkatan hakam di Pengadilan Agama. Dengan demikian, tatacara pengangkatan hakam harus berpedoman pada ketentuan hukum umum dan dikaitkan dengan ketentuan hukum acara perdata.

Berdasarkan ketentuan hukum Islam dan hukum acara perdata, pengusulan hakam datang dari pihak yang berperkara. Para pihak bebas mengusulkan siapa yang mereka inginkan untuk menjadi hakam, apakah berasal dari pihak keluarga atau pihak lain yang mereka percayai. Akan tetapi, apa yang mereka usulkan tidak mengikat Hakim. Oleh karena itu, Hakim menganjurkan kepada para pihak untuk mengusulkan beberapa orang dan dilengkapi dengan biodata masing-masing calon hakam. Dari keterangan biodata tersebut, hakim meneliti siapa yang paling tepat untuk menjadi hakam sesuai dengan persyaratan yang ditentukan dalam hukum 
Islam, yaitu cakap, jujur, memiliki kapasitas sebagai juru damai, berwibawa dan disegani oleh suami istri. Hakim sebaiknya menyuruh datang dan bertemu muka terlebih dahulu dengan orang-orang tersebut sebelum mengangkat mereka sebagai hakam. Adapun tujuan dari pertemuan tersebut adalah agar hakim mendapat kesan apakah orang-orang yang diusulkan para pihak tersebut memang tepat untuk diangkat menjadi hakam. Jika Hakim berpendapat bahwa orang-orang yang diusulkan tersebut kurang tepat, maka Hakim dapat mengangkat orang lain. Tetapi sebaiknya Hakim menanyakan pendapat para pihak. Karena sangat tepat apabila hakam yang hendak diangkat mendapat persetujuan dari para pihak, sehingga tidak ada hambatan psikologis antara hakam dengan para pihak dalam melaksanakan perdamaian dalam perkara syiqaq tersebut.

Pengangkatan hakam dilakukan melalui "putusan sela" bukan "penetapan (beschikking)". Karena pengangkatan hakam menurut hukum acara adalah tindakan insidentildari Hakim sebelum Hakim menjatuhkan putusan akhir. Dalam putusan sela tersebut berisi tentang nama-nama orang yang diangkat menjadi hakam, tugas yang harus dilakukan oleh para hakam, batas jangka waktu tugas hakam serta penundaan pemeriksaan atau penjatuhanputusan akhir. (Harahap, 1993: 275). Jadi, selama masa jangka waktu tugas hakam masih berjalan, maka pemeriksaan perkara ditunda.

Berkaitan dengan kekuatan mengikat pendapat atau usul hakam dalam proses penyelesaian perkara syiqaq tidak diatur dalam Pasal 76 ayat (2) Undang-Undang Nomor 7 Tahun 1989. Hal ini mungkin dikarenakan fungsi hakam hanya untuk mendamaikan kedua pihak (suami istri) yang sedang berselisih dan tidak diserta kewenangan apapun. Undang-undang tidak memberikan kewenangan kepada hakam untuk menjatuhkan putusan. Kedudukan hakam sebagai arbiter yang diatur dalam 76 ayat (2) UndangUndang Nomor 7 Tahun 1989 berbeda dengan posisi arbiter dalam UndangUndang Nomor 30 Tahun 1999 tentang Arbitrase dan Alternatif Penyelesaian Sengketa (AAPS), yang memberi wewenang kepada arbiter untuk menjatuhkan putusan yang bersifat mengikat dan mempunyai kekuatan eksekutorial. Menurut Yahya Harahap, Hakam yang diatur dalam 76 ayat (2) Undang-Undang Nomor 7 Tahun 1989 lebih menitik beratkan kewajibannya daripada kewenangan. Hakam wajib berusaha untuk mencari upaya penyelesaian, tapi tidak berwenang untuk memutuskan.

Hakam hanya memiliki "hak mengusulkan" atau "mengajukan pendapat" kepada hakim yang mengangkatnya. Usul atau pendapat tersebut sama sekali tidak mengikat hakim. Undang-undang memberikan kebebasan sepenuhnya kepada hakim untuk menilai apakah dia akan menerima atau tidak tentang apa yang diusulkan oleh hakam. (Harahap, 1993: 277). Meskipun pada prinsipnya usul hakam tidak mengikat, tetapi kalau usul tersebut didukung oleh alasan-alasan yang logis, maka kurang bijaksana jika hakim mengabaikannya. Sekurang-kurangnya, usul hakam tersebut harus diperhatikan Hakim dalam memgambil keputusan. Apa lagi jika usul yang diajukan hakam benar-benar didukung alasan yang reasonable, kemudian hal itu dikonfrontir kepada suami istri, dan ternyata usul itu sejalan dengan hasil konfrontir, maka dalam kondisi tersebut maka Hakim wajib terikat kepada usul hakam. Sebaliknya, jika hasil konfrontir berbeda dengan apa yang diusulkan hakam, maka Hakim tidak terikat dengan usul atau pendapat hakam tersebut (Harahap, 1993: 278). 


\section{Pelaksanaan Pengangkatan Hakam di Pengadilan Mahkamah Syar'iyah Malaysia.}

Undang-Undang Keluarga Islam (Wilayah Persekutuan) tahun 1984 dengan Akta Nomor 303 (Act 303 Islamic Family Law [Federal Territories] Act 1984) adalah produk hukum yang menjadi model dari Enakmen-enakmen hukum keluarga Islam Malaysia. Akta ini merupakan "akta bagi mengkanunkan peruntukan-peruntukan tertentu Undang-Undang Keluarga Islam mengenai perkahwinan, perceraian, nafkah, penjagaan, dan lain-lain perkara berkaitan dengan kehidupan keluarga".

Akta ini terdiri dari 10 bagian, yaitu:

1. Bahagian I Permulaan mencakup seksyen 1-6

2. Bahagian II Perkahwinan mencakup seksyen 7-24

3. Bahagian III Pendaftaran Perkahwinan mencakup seksyen 25-34

4. Bahagian IV Penalti dan Pelbagai Peruntukan Berhubungan dengan Akad nikah dan Pendaftaran Perkahwinan mencakup seksyen 35-44

5. Bahagian V Pembubaran Perkahwinan mencakup seksyen $45-58$

6. Bahagian VI Nafkah istri, Anak dan lain-lain mencakup seksyen 59-80

7. Bahagian VII Penjagaan mencakup seksyen 81-107

8. Bahagian VIII Pelbagai mencakup seksyen 108-122

9. Bahagian IX Penalti mencakup seksyen 123-133

10. Bahagian X Am mencakup seksyen 134-135.

The Islamic Family Law Act (IFLA) 1984 No. 303 merupakan upaya yang telah dilakukan oleh Pemerintah Federal untuk memiliki model hukum untuk administrasi hukum keluarga Islam di Malaysia. Hukum perceraian Malaysia diatur dalam Akta Undang-Undang Keluarga Islam (Wilayahwilayah Persekutuan) Tahun 1984 Bagian V tentang Pembubaran Perkawinan. Dan setiap wilayah-wilayah persekutuan memiliki Enakmen Undang-undang Keluarga Islam sendiri, (Hak, 2008: 17), yang berpedoman pada The Islamic Family Law Act (IFLA) 1984 No. 303.Di dalam undangundang tersebut, dijelaskan macam-macam bentuk perceraian yang terdapat di negara Malaysia, antara lain: Perceraian dengan talaq atau dengan perintah, perceraian dengan syiqaq dan pengangkatan hakam, perceraian dengan khulu' atau talaq tebus, perceraian di bawah ta'liq atau janji, perceraian dengan li'an, perceraian dengan fasakh. (Enakmen Keluarga Islam Selangor, 2003, dan Akta Undang-Undang Keluarga Islam (Wilayah Persekutuan), 2006),

Penyelesaian perkara syiqaq dan pengangkatan hakam (Hak, 2008: 23) berdasarkan seksyen 48 Enakmen Keluarga Islam Selangor Tahun 2003 seksyen 48 Akta Undang-Undang Keluarga Islam (Wilayah Persekutuan) 1984 dapat diterapkan dalam prosedur penyelesaian perceraian secara talak dan khuluk.Berdasarkan Enakmen Keluarga Islam Selangor Tahun 2003 seksyen 47 dan Akta Undang-Undang Keluarga (Wilayah Persekutuan) 1984 seksyen 47 menjelaskan bahwa apabila kedua suami istri atau salah satu pihak suami atau istri ingin membubarkan perkawinan secara talak maka permohonan perceraian tersebut dapat diajukan kepada Mahkamah Rendah Syariah di tempat suami istri tersebut tinggal. Dalam permohonan tersebut harus berisi: 
a. particulars of the marriage and the names, ages and sex of the children, if any, of the marriage;

b. particulars of the facts giving the Court jurisdiction under section 45;

c. particulars of any previous matrimonial proceedings between the parties, including the place of the proceedings;

d. a statement as to the reasons for desiring divorce;

e. a statement as to whether any, and, if so, what steps had been taken to effect reconciliation;

f. the terms of any agreement regarding maintenance and habitation of the wife and the children of the marriage, if any, the care and custody of the children of the marriage, if any, and the division of any assets acquired through the joint effort of the parties, if any, or, where no such agreement has been reached, the applicant's proposals regarding those matters; and

g. particulars of the order sought.

Apabila kedua pihak setuju untuk bercerai dan Mahkamah telah menemukan bahwa perkawinan antara kedua suami istri tersebut telah terjadi perpecahan, lalu Mahkamah akan menyuruh suami untuk melafazkan talak 1 dihadapan Mahkamah. Kemudian Mahkamah mengesahkan lafaz cerai suami dan mengeluarkan surat perintah perceraian. Selanjutnya suami dan istri dapat menerima rekod perceraian dan membawanya ke Jabatan Agama Islam untuk didaftarkan pada bagian perceraian.

Pada Jabatan Agama Islam, suami dan istri menyerahkan rekod perceraian dengan dilampiri dokumen: Akta Nikah atau Akta Ruju', KTP dan Surat Perintah Daftar Cerai. Serta membayar iuran Daftar Cerai (sesuai dengan ketentuan yang telah ditetapkan pada setiap negeri-negeri). Kemudian, Jabatan Agama Islam mencatat dalam Daftar Cerai dan mengeluarkan Akta Cerai. Apabila salah satu pihak tidak setuju untuk bercerai, atau jika menurut Mahkamah ada kemungkinan yang wajar bagi suatu perdamaian antara para pihak, maka Pengadilan akan menunjuk suatu Jawatan kuasa Pendamai. Jawatan kuasa Pendamai terdiri dari Pegawai Agama sebagai Pengerusi (Ketua) dan seorang wakil suami dan seorang wakil istri. Pengadilan akan memberikan prioritas kepada kerabat dekat para pihak yang mengetahui posisi kasus tersebut.

Mahkamah memberikan arahan atau penjelasan kepada Jawatan kuasa Pendamai, dan Jawatan kuasa Pendamai harus bertindak sesuai dengan arahan Mahkamah. Jika Jawatan kuasa Pendamai tidak dapat menyetujui arahan yang diberikan oleh Mahakamah atau Mahkamah tidak puas terhadap usaha-usaha perdamaian yang dilakukan oleh Jawatan kuasa Pendamai, maka Mahkamah boleh memecat Jawatan kuasa Pendamai tersebut dan menunjuk Jawatan kuasa Pendamai yang lain untuk menggantikannya.

Jawatan kuasa Pendamai diberi waktu selama 6 (enam) bulan atau dalam waktu yang telah ditetapkan oleh Mahkamah untuk menjalankan proses perdamaian. Jawatan kuasa Pendamai diperbolehkan untuk memanggil dan memberi peluang pada suami dan istri serta orang lain yang dapat memberikan masukan. Jawatan kuasa dapat melakukan penyelidikan yang sesuai dengan kepentingan untuk perdamaian tersebut. Selama proses 
perdamaian ini, Peguam Syarï (Advokat) tidak diperkenan hadir atau bertindak untuk para pihak. Para pihak juga tidak dapat diwakili oleh orang lain kecuali kerabat dekatnya, tanpa izin dari Jawatan kuasa Pendamai. Jika Jawatan kuasa Pendamai melaporkan bahwa perdamaian telah tercapai dan para pihak telah hidup bersama kembali sebagai suami istri, maka Mahkamah harus menolak permohonan cerai tersebut. Sebaliknya, jika Jawatan kuasa Pendamai gagal mendamaikan para pihak, maka harus dibuat sertifikat beserta dengan saran-saran yang dianggap patut yang berhubungan dengan nafkah dan hadanah anak-anak, pembagian harta dan hal-hal lain yang terkait dengan perkawinan tersebut. Setelah laporan diterima oleh Mahkamah, maka Mahkamah memerintah suami untuk melafazkan satu talak. Apabila suami tidak hadir ke Mahkamah atau suami enggan melafazkan talak, maka Mahkamah harus merujuk kasus tersebut kepada hakam sesuai dengan seksyen 48 IFLA 1984 karena telah terjadi syiqaq antara suami istri tersebut. Suatu keadaan tertentu yang dapat dinyatakan syiqaq adalah:

a. perkelahian yang kerap antara suami dan isteri itu sama ada oleh sebab

i. nusyuz isteri;

ii. kezaliman suami;

iii. ketidaktentuan siapa yang benar antara kedua-duanya; atau

iv. salah satu pihak atau kedua-dua pihak berdusta atau menuntut yang bukan hak.

b. perkelahian yang kerap antara suami dan isteri sehingga menimbulkan kesukaran menjalankan tanggungjawab masingmasing dan saling tuduh menuduh tidak melaksanakan hak sebagai suami dan isteri;

c. suami atau isteri saling tuduh-menuduh antara keduanya mempunyai hubungan yang melampaui Hukum Syarak dengan perempuan atau lelaki lain;

d. perkelahian yang kerap hingga menyebabkan pukul-memukul;

e. salah seorang meninggalkan rumah kediaman, tidak tinggal bersama sedangkan punca sebenar tidak dapat dibuktikan oleh kedua-dua pihak di hadapan Mahkamah;

f. suami atau isteri saling tuduh-menuduh antara keduanya mengenai tanggungjawab masing-masing terhadap anak-anak sehingga berlaku pertikaian dan perkelahian yang kerap;

g. jika didapati bahawa sebarang tuntutan oleh isteri untuk mendapatkan pembubaran perkahwinan tidak sabit dan ditolak oleh Mahkamah atas alasan dia tidak dapat membuktikan kebenarannya dan Mahkamah mendapati pertikaian itu masih lagi berterusan atau berulang antara suami isteri tersebut; atau

h. apa-apa tindakan yang menyebabkan darar syarie ke atas isteri atau suami. (Kaedah-Kaedah Hakam (Negeri Selangor) 2014).

Apabila Mahkamah telah menetapkan bahwa antara suami istri telah terjadi syiqaq, maka sesuai dengan Hukum Syarak, Mahkamah dapat melantik dua orang hakam (penimbangtara/arbiter) satu orang dari pihak suami dan satu orang dari pihak istri, yang diutamakan adalah saudara dekat yang mengetahui permasalahan suami istri tersebut. Persyaratan 
untuk dapat menjadi hakam dari saudara dekat suami dan istri adalah: Beragama Islam, Laki-laki, Berakal dan Baligh (mukallaf), adil dan amanah, dan mempunyai pengetahuan asas dalam hal kekeluargaan dan Hukum Syarak.Hakam harus mendapat kuasa penuh dari pihak prinsipalnya. Suami boleh memberi kuasa penuh kepada Hakam suami untuk melafazkan talak atau khuluk bagi pihak suami dihadapan Mahkamah, dan istri dapat memberi kuasa penuh kepada Hakam istri untuk menerima Lafaz khuluk dihadapan Mahkamah.

Sebelum melaksanakan tugasnya, Hakam mendapat pengarahan terlebih dahulu dari Mahkamah. Jika Hakam tidak setuju dengan arahan Mahkamah atau Mahkamah tidak puas dengan cara Hakam menjalankan tugasnya sebagai hakam (penimbangtaraan), maka Mahkamah dapat memecat hakam tersebut dan melantik Hakam yang lain.

Fungsi Hakam adalah:

a. To explain to the parties the role of the hakam in resolving their problem from the Islamic viewpoint;

b. To look at the background if the parties and to discuss the matter with them;

c. To read the notes of evidence in order to have a thorough understanding of the case;

d. To underline the merits of a peaceful settlement and demerits of divorce and its effect on individual, children, community, property, joint savings, matrimonial property, and to explain to the parties the need for payment of nafkah 'iddah and mut'ah following divorce as well as the social problems that divorce create;

e. To endeavor to effect a reconciliation between the parties, failing which, to decree a divorce;

f. To report to the Court the result of the arbitration and for the decision to be translated into a Court Order. (Hak, 2006: 54).

Pada proses Tahkim, suami dan istri hadir pada hari dan tanggal yang telah ditentukan dan memberikan keterangan kepada hakam. Proses Majelis Tahkim dilaksanakan paling lama 3 (tiga) bulan. Apabila dalam melaksanakan tugas Majelis Tahkim tersebut, kedua Hakam berpendapat bahwa tidak tercapai perdamaian antara suami istri, maka kedua Hakam harus menentukan pihak mana yang menjadi penyebab terjadinya syiqaq. Jika shiqaq itu: (a) ditemukan berasal dari suami atau kedua suami dan istri, kedua Hakam harus mengusulkan perceraian secara talak; (b) ditemukan berasal dari istri, kedua Hakam harus mengusulkan perceraian secara khuluk dan harga 'iwadh harus diputuskan oleh Hakam; (c) tidak dapat ditentukan penyebabnya dan tuntutan perceraian dibuat oleh suami, maka kedua Hakam harus mengusulkan perceraian secara talak; atau (d) tidak dapat ditentukan penyebabnya dan tuntutan perceraian dibuat oleh istri, maka kedua Hakam harus mengusulkan perceraian secara khuluk dan harga 'iwadh harus diputuskan oleh Hakam. (Kaedah-Kaedah Hakam (Negeri Selangor) 2014). Jika kedua Hakam dalam Majelis Tahkim memutuskan bahwa perkawinan tersebut dibubarkan secara talak, maka talak harus dilafazkan oleh Hakam suami dihadapan dan dengan kebenaran Mahkamah. Dan talak Hakam adalah talak ba'in. Apabila kedua Hakam dalam Majelis Tahkim memutuskan supaya perkawinan dibubarkan secara khuluk dan 'iwadh telah disempurnakan oleh istri dalam Majelis Tahkim, 
maka khuluk harus dilafazkan dihadapan dan dengan kebenaran Mahkamah. Selanjutnya, Hakam menyampaikan Keputusannya kepada Hakim Mahkamah. Keputusan Majelis Tahkim bersifat muktamad (final) dan tidak dapat dilakukan upaya hukum banding.

Setelah Mahkamah menerima laporan keputusan Hakam, maka Mahkamah memerintahkan suami atau Hakam suami untuk melafazkan satu talak, kemudian Mahkamah mengeluarkan Surat Perintah Perceraian. Selanjutnya suami dan istri akan menerima rekod perceraian dan segera menyerahkan rekod perceraian tersebut kepada Jabatan Agama Islam untuk daftar cerai dengan dilampiri : Akta Nikah atau Akta Ruju', KTP dan Surat Perintah Daftar Cerai dari Mahkamah serta membayar uang iuran sesuai dengan ketentuan yang telah ditetapkan pada setiap negeri. Selanjutnya, Jabatan Agama Islam akan mencatat dalam Daftar Cerai dan mengeluarkan Akta Cerai suami istri tersebut.

\section{Kesimpulan}

Indonesia dan Malaysia adalah sama-sama negara muslim yang memberlakukan hukum keluarga Islam pada masyarakat yang beragama Islam. Namun demikian, dalam hal pelaksanaan pengangkatan hakam pada penyelesaian perkara syiqaq terdapat perbedaan. Hakam di Pengadilan Agama Indonesia hanya berfungsi untuk mendamaikan kedua pihak (suami istri) yang sedang berselisih dan tidak disertai kewenangan memutus. Jadi hakam hanya bertugas sebagai mediator bukan arbiter. Di Mahkamah Syar'iyyah Malaysia, Hakam harus mendapat kuasa penuh dari pihak prinsipalnya. Suami boleh memberi kuasa penuh kepada Hakam suami untuk melafazkan talak kepada pihak istri dihadapan Mahkamah, dan istri dapat memberi kuasa penuh kepada Hakam istri untuk melakukan khuluk atau menerima lafaz talak di hadapan Mahkamah.

\section{DAFTAR PUSTAKA}

Akta Undang-Undang Keluarga Islam (Wilayah Persekutuan), 2006

Al Maraghi, Ahmad Mushthafa, 1974, Tafsir al Maraghi, Juz 5, Mesir, Mushthafa al Babi al Halabi, diterjemahkan oleh Bahrun Abubakar dan Hery Noer Aly, Terjemah Tafsir al-Maraghi, 1986, Semarang: Toha Putra.

Enakmen Keluarga Islam Selangor, 2003.

Hak, Nora Abdul, Hakam/Tahkim (Arbitration) in Resolving Family Disputes: The Practice in The Syariah Courts of Malaysia and Singapore, Asian Journal of International Law, Volume 1 Issue 14 Juni 2006.

Harahap, M. Yahya, 1993, Kedudukan, Kewenangan dan Acara Oeradilan Agama, Jakarta: Pustaka Kartini.

Kaedah-Kaedah Hakam (Negeri Selangor) 2014.

Manan, Abdul, 2005, Penerapan Hukum Acara Perdata di Lingkungan Peradilan Agama, Jakarta: Kencana Prenada Media.

Peraturan Pemerintah Nomor 9 Tahun 1975 tentang Peraturan Pelaksanaan Undang-Undang Nomor 1 Tahun 1974 tentang Perkawinan.

Ridha, Muhammad Rasyid, t.t, Tafir Al Manaar, Juz III, Bairut Libanon: Darul Ma'ritah. 
Sabiq, Sayyid, Fiqhussunnah, Juz 8, dialihbahasakan oleh Mohammad Thalib, Bandung: Al Ma'arif.

Shabuni, Muhammad Ali Ash, t.t, Tafsir Ayat al Ahkam min al Qur'an, Juz 1, Bairut: Daarul Qur'anul Karim.

Soemiyati, 1982, Hukum Perkawinan Islam dan Undang-Undang Perkawinan (Undang-Undamg Nomor 1 Tahun 1974 tentang Perkawinan), Yogyakarta: Liberty.

Somad, Abd. 2012, Hukum Islam: Penormaan Prinsip Syariah Dalam Hukum Indonesia, Jakarta: Kencana Prenada Media.

Taisyir Rajab at Tamimi, 2009/1430, Ath Thalaq Baina Ta'assufil Muthalliq wa Tafriqul Qadhi (Dirasatun Fiqhiyah Muqaranah bi Qawaninil Ahwalusy Syakhshiyyah fi Baidil Buldan al-Arabiyyah wal Muhakkamul Falishthiniyyah), Kairo, Darul Fikri.

Undang-Undang Nomor 1 Tahun 1974 tentang Perkawinan.

Undang-undang Nomor 7 Tahun 1989 tentang Peradilan Agama.

Undang-Undang Nomor 3 Tahun 2006 tentang Perubahan Atas Undangundang Nomor 7 Tahun 1989 tentang Peradilan Agama.

Undang-undang Nomor 50 Tahun 2009 tentang Perubahan Kedua atas Undang-undang Nomor 7 Tahun 1989 tentang Peradilan Agama.

Wahbah Az-Zuhayly,1989,Al-Fiqh Al-Islami Wa'adillatuh, Juz VII, Cet.III, Dar Al Fikir, Damsiq-Syiria. 